\title{
Detection of total hip arthroplasty at airport securities
}

\section{Ashok Raju Gottemukkala, Praful Kilaru, Pushpak Reddy Chada*, Rahul Suna, Maryada Venkatwar Reddy, Annapareddy Venkata Gurava Reddy}

Department of Orthopaedics, Sunshine Hospitals, Hyderabad, Telangana, India

Received: 06 August 2020

Revised: 14 November 2020

Accepted: 17 November 2020

*Correspondence:

Dr. Pushpak Reddy Chada,

E-mail: chadapushpakreddy21@gmail.com

Copyright: (c) the author(s), publisher and licensee Medip Academy. This is an open-access article distributed under the terms of the Creative Commons Attribution Non-Commercial License, which permits unrestricted non-commercial use, distribution, and reproduction in any medium, provided the original work is properly cited.

\section{ABSTRACT}

Background: In era of increased air travel, airport security screening measures has been increased. A lot of anxiety to the patient, that may trigger an alarm at airport securities post-surgery. The purpose of this study is to find out experiences of patients after total hip arthroplasty (THA) passing through airport security.

Methods: A retrospective case series of 269 THA patients in a single high-volume center from January 2016 to June 2018, who had passed through airport security and met inclusion criteria. Patient were contacted during their regular follow ups or via phone. The patients were asked for alarm trigger, perceived inconvenience, whether security officials asked to show documentation regarding prosthesis, and any extra screening procedures check measures.

Results: Out of 269 patients, 52 patients met inclusion criteria travelling by airplane. 27 patients reported alarm trigger. 7 patients had to undergo additional security check measures. $43 \%$ of the patients believed that having their THA increased the inconvenience while traveling.

Conclusions: This study provides information to surgeons regarding airport travel post THA. Patients can be counselled regarding the inconvenience and to be prepared for delays in airport and to be prepared to present documentation of their prosthesis.

Keywords: Airport, Total hip arthroplasty, Security check

\section{INTRODUCTION}

The number of joint replacement surgeries performed worldwide continues to increase annually and it has been predicted that there will be 5,27,000 total hip replacements and 3.48 million total knee replacements worldwide annually by the end of $2030 .{ }^{1}$ The frequency of air travel increased in the recent decade and awareness of terrorism rose the sensitivity of security checks. Patient frequently ask whether any issue regarding airport travel post total hip replacement.

There are no reports published from India examining how this affects patients who have undergone total hip arthroplasty. There have been several studies that have reported that $47 \%$ to $88 \%$ of patients trigger the security checkpoint alarms with their orthopaedic hardware. ${ }^{2}$ But factors like speed of passing through the metal detector arch, patient BMI, implant weight and composition of metal may alter the results. ${ }^{3}$ In a study done by Josef $G$ et al stated that implants weighing more than $145 \mathrm{~g}$ triggered an alarm. ${ }^{4}$ Implants with cobalt chromium alloys were more sensitive to metal detector than titanium and stainless steel. $^{5}$

The purpose of this study was to assess the patients who had passed through airport security and to find out the incidence of alarm trigger, inconvenience in airport, extra security check measures and role of document regarding implant in the body. 


\section{METHODS}

This is a retrospective case study. The eligibility criteria for selection of patients sampling in the study included are, firstly, all THA patients operated between January 2016 to June 2018 in Sunshine Hospitals, Hyderabad and secondly all patients travelling through airport security. Patients were contacted during follow ups or via phone call. Patients were asked for a set of questions regarding alarm trigger in airport, perceived inconvenience, extra security check measures, whether they have taken any document from hospital regarding implant, and whether they were asked to show document.

All data were put into a Microsoft excel for statistical analysis. Statistical comparisons between the present study and their comparative recent study were compared using a $\mathrm{Z}$ test for population proportions. A $\mathrm{p}$ value of less than 0.05 was considered statistically significant.

\section{RESULTS}

Out of 269 patients contacted during study period, 52 patients had history of traveling through airport security (right sided THA- 27, left THA-19 and bilateral THA-6) (Figure 1). Of these 52 patients, $27(52 \%)$ reported that they had alarm trigger. 18 (34\%) patients took document from hospital while travelling. 11 patients were asked to show document regarding the implant, rest were given oral explanation. 7 out 52 patients underwent extra security check measures. Out of which, 4 patients were asked to show scar of surgery (Figure 2). One patient had to undergo full body search in American embassy. Overall, 22 of the 52 patients $(42 \%)$ believed that having a joint prosthesis increased the inconvenience of airplane travel.

When compared to Issa et al in their study, patients had reported that alarms were triggered in 10 out of $51(20 \%$; $\mathrm{p}=0.0000)$ patients. $^{1} 13$ of $51(25 \% ; \mathrm{p}=0.0023)$ reported that having a prosthesis caused them inconvenience while travelling. Both were statically significant. However, the incidence of those subjected to more invasive search methods was similar ( $n=5$ of 51 patients; $p=0.2354$ ) not statistically significant.

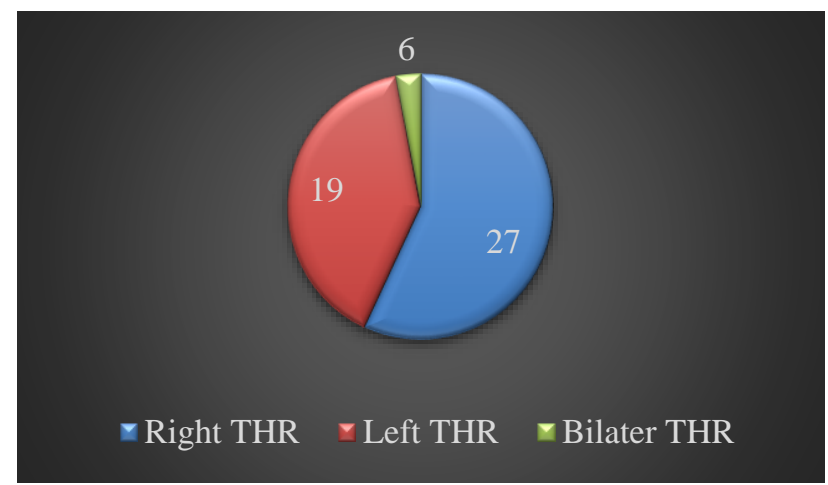

Figure 1: Nature of THR (total hip replacement).

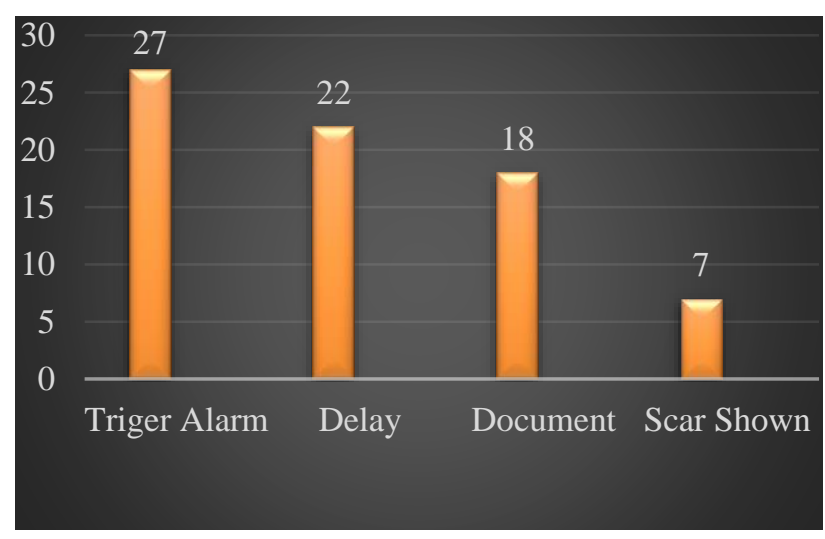

Figure 2: Nature of security check.

Table 1: Gender variation.

\begin{tabular}{|lll|}
\hline Security check & Male & Female \\
\hline Trigger alarm & 15 & 12 \\
\hline Delay & 12 & 10 \\
\hline Document & 10 & 8 \\
\hline Shown scar & 4 & 3 \\
\hline
\end{tabular}

Table 2: Side variation.

\begin{tabular}{|llll|}
\hline Side & Right & Left & Bilateral \\
\hline Tigger alarm & 13 & 10 & 4 \\
\hline Delay & 11 & 8 & 3 \\
\hline Document & 8 & 7 & 3 \\
\hline Shown scar & 1 & 4 & 2 \\
\hline
\end{tabular}

\section{DISCUSSION}

Joint arthroplasty implants are commonly detected at airport securities even with low security standards. ${ }^{6}$ Airport metal detectors use electromagnetic fields to detect metals. These equipment create electromagnetic fields from the source and when a metal is passed through these fields undergo temporary magnetization and generate a conduction, disturbing the electromagnetic field allowing a trigger of alarm. ${ }^{7}$ Magnetic metals such as iron, nickel and cobalt produce induction currents, which are detected by the device. Detection is known to depend on a variety of factors: sensitivity setting of the detector, metallurgical composition, mass and even the side of the implant has all been implicated. ${ }^{8}$

Pearson et al found that ferrous content in implant alloy was the cause of alarm trigger. ${ }^{9}$ Cobalt-chromium and titanium implants were detected more often than were those made of stainless steel. This pattern was consistent among the different types of implants, with titanium plates being detected more often than stainless-steel plates and titanium prostheses being detected more often than stainless-steel prostheses. ${ }^{6}$

Asch et al conducted a sensitivity test by 3 types of metal detectors and concluded that orthopaedic trauma implants 
like screws, plates and pins went undetected by arch detectors but detected by hand detectors, where as in joint replacements were detected by arch detectors. ${ }^{10}$ In our study $52 \%$ of patients reported that they had alarm trigger at airport.

Abbassian et al found that the knee prostheses are significantly more likely to be detected than hip prostheses. Interestingly, both implants have similar weight and magnetic metal composition. The difference in the detection rate might, therefore, be because hip prostheses are deep, intramedullary implants that have a greater degree of shielding by way of cement, bone and soft tissues. ${ }^{8}$

Ramirez et al compared the detection of orthopedic implants by metal detectors found that 77 and $88 \%$ of all arthroplasties were detected using low and high-sensitivity metal detectors, respectively. ${ }^{6}$ Furthermore, these arthroplasties were more likely to be detected than a variety of other implants Therefore, they concluded that, amongst patients with orthopaedic implants, those with joint arthroplasties were far more likely to experience inconvenience when travelling.

No correlation was found between the patient body mass index and the likelihood of detection with the archway detector.

The main limitation of the study is, it is a small number case series and need to be studied in a larger group.

\section{CONCLUSION}

We advise surgeons to provide documentation regarding surgery and prosthesis to prove the presence of an orthopaedic implant to all patients. Chances of invasive searches is less likely after showing documentary evidence in some patients. Patients should be counseled well that they should expect delays and be prepared for such inconveniences.
Funding: No funding sources

Conflict of interest: None declared

Ethical approval: Not required

\section{REFERENCES}

1. Kurtz S, Ong K, Lau E, Mowat F, Halpern M. Projections of primary and revision hip and knee arthroplasty in the United States from 2005 to 2030. J Bone Joint Surg Am. 2007;89:780e5.

2. Issa K, Pierce TP, Gwam C, Festa A, Scillia AJ, Mont MA. Detection of total hip arthroplasties at airport security checkpoints - how do updated security measures affect patients?. HIP Int. 2018;28(2):122-4.

3. Kamineni S, Legge S, Ware H. Metallic orthopaedic implants and airport metal detectors. J Arthroplas. 2002;17(1):62-5.

4. Grohs JG, Gottsauner-Wolf F. Detection of orthopaedic prostheses at airport security checks. J Bo Joint Surg. 1997;79(3):385-7.

5. Kuczmarski AS, Harris AP, Gil JA, Owens BD. Sensitivity of Airport Metal Detectors to Orthopaedic Implants. J Bone Joi Surg. 2018;6(7):e7.

6. Ramirez MA, Rodriguez EK, Zurakowski D, Richardson LC. Detection of orthopaedic implants in vivo by enhanced-sensitivity, walkthrough metal detectors. J Bone Joint Surg Am. 2007;89(4):742-6.

7. Beaupre GS. Airport detection of modern orthopedic implant metals. Clin Orthop Relat Res. 1994;(303):291-2.

8. Abbassian A, Datla B, Brooks RA. Detection of orthopaedic implants by airport metal detectors. Ann R Coll Surg Engl. 2007;89(3):285-7.

9. Pearson WG, Matthews LS. Airport detection of modern orthopaedic implant metals. Clin Orthop. 1992;280:261.

10. Asch M, Liu D, Mawdsley G. Detection of implanted metallic devices by airport security. J Vasc Interv Radiol. 1997;8(6):1011-4.

Cite this article as: Gottemukkala AR, Kilaru P, Chada PR, Suna R, Reddy MV, Reddy AVG.

Detection of total hip arthroplasty at airport securities. Int J Res Orthop 2021;7:48-50. 